03

\title{
Восстановление профиля поверхности капли жидкости на основе послойного лазерного зондирования
}

\author{
() И.Н. Павлов, И.Л. Расковская, Б.С. Ринкевичюс
}

Национальный исследовательский университет „МЭИ“, Москва

E-mail: inpavlov@bk.ru

Поступило в Редакцию 21 февраля 2017 г.

Разработана экспериментальная методика восстановления профиля поверхности капли жидкости на горизонтальной твердой подложке с использованием рефракционных изображений, полученных при послойном лазерном зондировании. Приведены примеры типичных изображений, полученных при вертикальном зондировании капель дистиллированной воды объемом 10-15 $\mu 1$ плоским коллимированным лазерным пучком, решена обратная задача рефракции и восстановлена глобальная форма поверхности капли. Указано, что для восстановления параметров микрорельефа поверхности целесообразно применять зондирование широким коллимированным пучком.

DOI: 10.21883/PJTF.2017.13.44807.16745

Для решения ряда фундаментальных и технологических задач, в частности для получения информации о структуре и свойствах поверхности раздела фаз, применяется метод анализа смачивания [1], основанный на измерении краевого угла смачивания каплей жидкости поверхности твердого тела. Однако такой подход дает удовлетворительные результаты только для капель относительно небольших размеров [2], так как не учитывает влияния силы тяжести на значения краевого угла и форму капель. Кроме того, реальные поверхности практически всегда являются шероховатыми или загрязненными, что сказывается на форме помещенных на такие поверхности капель. В ряде работ [3-6] рассматривались теоретические модели капель на неровной подложке с использованием полиномиальной аппроксимации контура капель, а также подходы, совмещающие в себе глобальную аппроксимацию формы капли с локальной аппроксимацией каких-либо ее геометрических параметров. Однако, как указано в [2], создание 


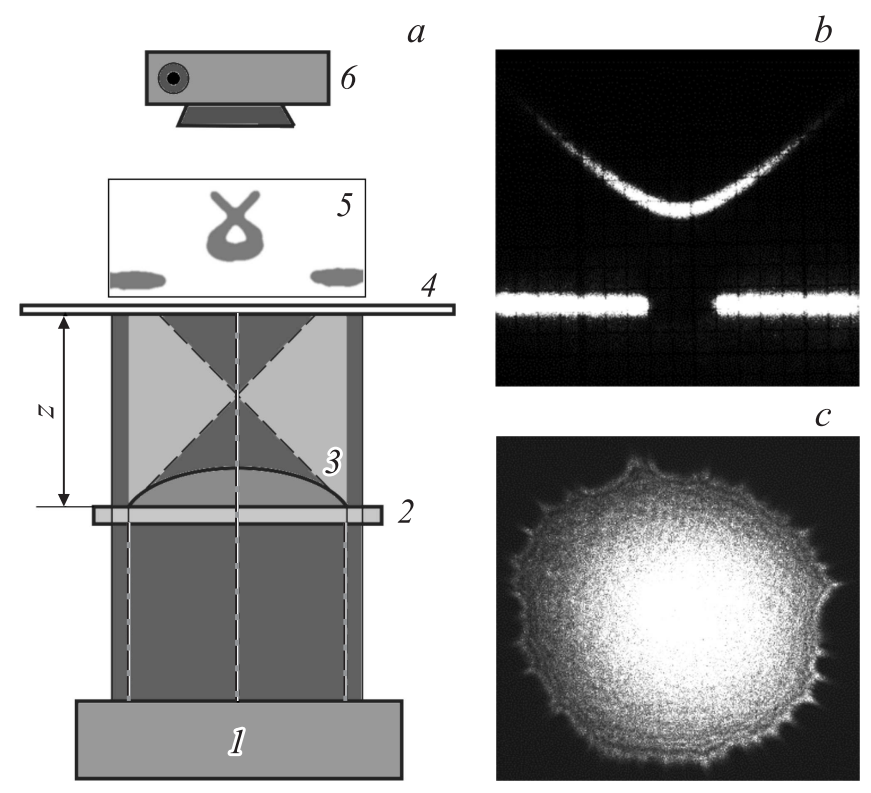

Рис. 1. Схема установки $(a)$ и характерные изображения при зондировании плоским $(b)$ и широким $(c)$ пучками.

единой модели в данной ситуации, очевидно, затруднено из-за многообразия факторов, влияющих на форму капли. Самостоятельный интерес имеет исследование неравновесных локальных углов смачивания при испарении и кристаллизации капли [7,8]. В связи с вышесказанным задачей данной работы является разработка экспериментальной методики, особенностью которой является послойное зондирование капли жидкости на твердой подложке вертикально направленным плоским лазерным пучком [9], что позволяет по рефракционным изображениям восстанавливать значения функции уровня поверхности в дискретном наборе сечений капли с последующей интерполяцией.

Схема экспериментальной установки показана на рис. 1, $a$. Она состоит из системы формирования зондирующего излучения: полупроводникового лазерного модуля с длиной волны излучения $650 \mathrm{~nm}$ и мощностью $5 \mathrm{~mW}$ и оптической системы формирования плоского

Письма в ЖТФ, 2017, том 43, вып. 13 
пучка 1 , представляющей собой телескопическую систему из двух цилиндрических линз - короткофокусной и длиннофокусной, прозрачной стеклянной подложки 2 (в экспериментах использовался набор пластинок с разной степенью шероховатости, но основной была пластинка с шероховатостью $\sim 6 \mathrm{~nm}$ ) с помещенной на ее поверхность исследуемой каплей 3 , диффузного экрана 4 и цифровой камеры 6 . Плоский лазерный пучок направляется вертикально снизу вверх, при этом часть его проходит через одно из сечений капли и преломляется в ней, другая часть проходит без искажения. Далее пучок попадает на экран 4, на котором формируется рефракционное изображение, типичный вид которого показан на вставке 5. Проекция неискаженной части пучка представляет собой отрезки прямой, а вид рефрагированной части (в центре изображения) зависит от расстояния $z$ между подложкой и экраном и положения сечения (рис. $1, b$ ). В ходе работы было произведено всего около 20 серий по 5 опытов в каждой. Выявлена высокая воспроизводимость результатов при соблюдении постоянства условий эксперимента. На рис. 1, $c$ для сравнения показан характерный вид изображения, получаемого при зондировании капли широким коллимированным пучком.

Для пояснения методики реконструкции профиля поверхности на основе рефракционных изображений воспользуемся приемом дискретизации сечения плоского волнового пучка, представив его в виде набора „точек“ (рис. 2). Пучок проходит через прозрачный объект, одна из поверхностей которого совпадает с плоскостью $\xi O \eta$ (плоскость подложки 2), в которой задается исходная дискретная структура сечения зондирующего лазерного пучка, а рельеф другой поверхности определяется функцией уровня $h(\xi, \eta)$, причем показатель преломления объекта отличается от показателя преломления окружающей среды на величину $\Delta n$. Если направление зондирования перпендикулярно плоскости $\xi O \eta$, то в приближении фазового экрана рефракционное смещение геометрооптических лучей в плоскости $x O y$ (плоскость экрана 4), находящейся на расстоянии $z(z \gg h(\xi, \eta))$ от плоскости $\xi O \eta$, определится соотношениями:

$$
x-\xi=z \Delta n \frac{\partial h}{\partial \xi}, \quad y-\eta=z \Delta n \frac{\partial h}{\partial \eta} .
$$

Из (1) следует, что рефракционное отклонение геометрооптических лучей определяется соответствующим поперечным градиентом уров-

Письма в ЖТФ, 2017, том 43, вып. 13 

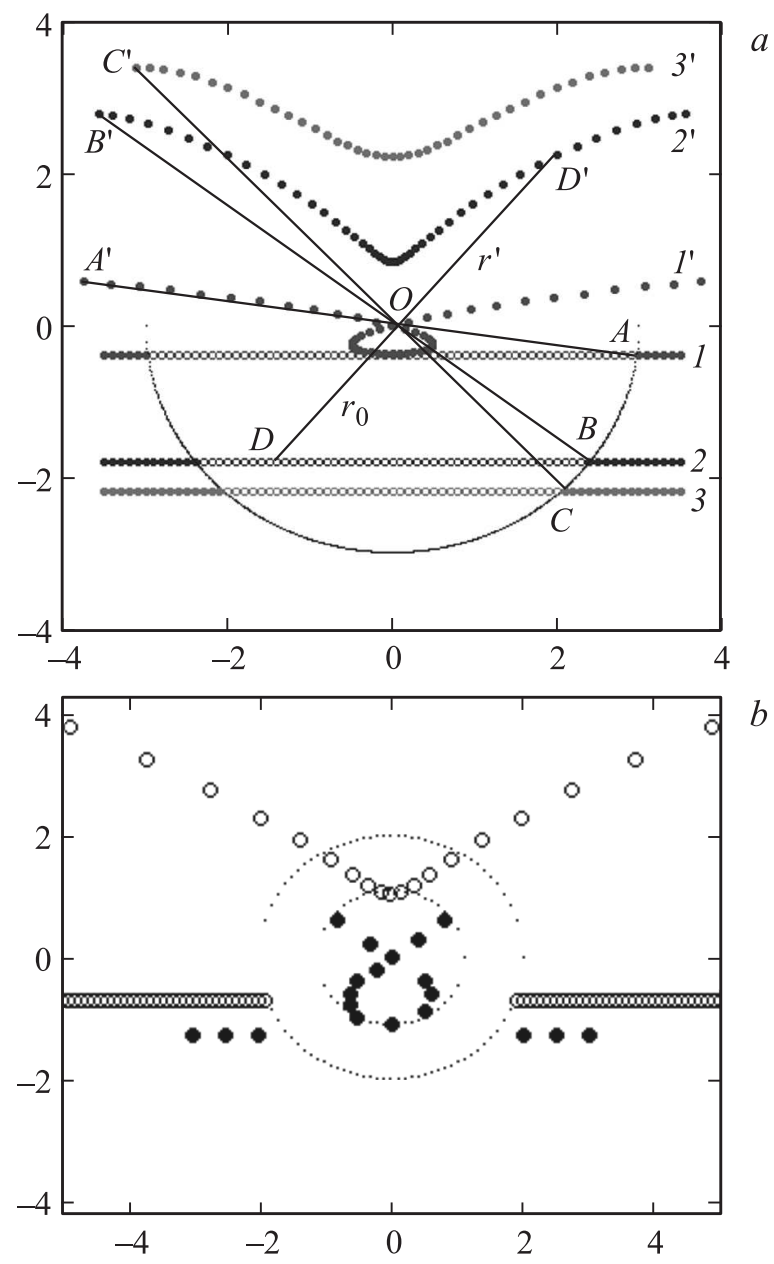

Рис. 2. Характерные расчетные и экспериментальные рефракционные изображения (размеры на осях указаны в относительных единицах, тонкой линией обозначена граница поверхности капли). $a$ - расчетные изображения; положения сечений относительно центра: $1-0.4,2-1.8,3-2.2 \mathrm{~mm}$; расстояние от подложки до плоскости наблюдения $z=19 \mathrm{~mm} . b$ - пример оцифрованных экспериментальных изображений, полученных для капли радиусом $2 \mathrm{~mm}$ на расстоянии от подложки до экрана $z=19 \mathrm{~mm}$ в двух разных сечениях.

Письма в ЖТФ, 2017, том 43, вып. 13 
ня поверхности. Смещение структурных элементов пучка, в данном случае набора точек, относительно их исходного положения может быть зарегистрировано экспериментально на заданном расстоянии $z$, и составляющие градиента уровня поверхности определятся как

$$
\frac{\partial h}{\partial \xi}=\frac{(x-\xi)}{z \Delta n}, \quad \frac{\partial h}{\partial \eta}=\frac{(y-n)}{z \Delta n} .
$$

По найденным из уравнений (2) составляющим градиента уровня и заданной границе поверхности $\eta_{0}(\xi)$, определяемой из условия $h(\xi, \eta)=0$, восстанавливается функция $h(\xi, \eta)$.

При исследовании осесимметричных объектов можно использовать плоские лазерные пучки [9-11]. Методика нахождения градиента функции уровня иллюстрируется рис. 2, $a$, на котором представлены характерные рефракционные изображения, наблюдаемые в плоскости $x O y$ при зондировании плоскими пучками осесимметричной капли радиусом $R=3 \mathrm{~mm}$ и высотой $1 \mathrm{~mm}$, профиль которой задан полиномом четвертой степени и краевой угол меньше $90^{\circ}$. Плоские лазерные пучки на уровне подложки в сечениях 1,2,3 визуализируются как отрезки, пересекающие границу поверхности капли. Структурные элементы пучков (показаны сплошными кружками) смещаются в радиальном направлении из-за преломления на поверхности, и в плоскости $x O y$ формируются изображения $1^{\prime}, 2^{\prime}, 3^{\prime}$. В этом случае система уравнений (2) эквивалентна соотношению

$$
\frac{\partial h(r)}{\partial r}=\frac{r_{0}+r^{\prime}}{z \Delta n}
$$

где $r_{0}$ - расстояние от центра капли до некоторого структурного элемента исходного пучка, $r^{\prime}-$ расстояние от центра капли до того же структурного элемента рефрагированного пучка.

Левая часть (3) представляет собой тангенс угла наклона касательной к поверхности капли в главном сечении, который в произвольной точке $D$ может быть найден при подстановке экспериментальных значений $r_{0}$ и $r^{\prime}$, соответствующих этой точке. Для точек $A, B, C$, расположенных на границе поверхности, угол наклона касательной совпадает с локальными значениями краевого угла смачивания $\theta$ в этих точках. Для осесимметричной капли $\theta(A)=\theta(B)=\theta(C)$, тогда $A A^{\prime}=B B^{\prime}=C C^{\prime}=z \Delta n \operatorname{tg} \theta$, откуда следует, что точки $A^{\prime}, B^{\prime}, C^{\prime}$ лежат

Письма в ЖТФ, 2017, том 43, вып. 13 


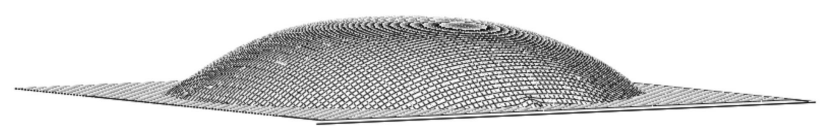

Рис. 3. Восстановленная форма капли.

на окружности с центром в точке $O$ и радиусом

$$
R^{\prime}=z \Delta n \operatorname{tg} \theta-R \text {. }
$$

На рис. 2, а показаны характерные расчетные рефракционные изображения при зондировании капли плоским пучком в трех сечениях. Характерные экспериментальные оцифрованные изображения представлены на рис. 2, $b$, на рис. 3 показана восстановленная на их основе форма поверхности капли.

Изображения, аналогичные показанным на рис. 2, $b$, стабильно наблюдались в эксперименте для капель с радиусом около $2 \mathrm{~mm}$ и объемом не более $10 \mu 1$. Анализ результатов моделирования „глобальной“ поверхности капли полиномами $k$-й степени показал, что такие рефракционные картины возможны только при $k>2$, т. е. традиционная аппроксимация полиномами второй степени даже для таких относительно небольших капель оказывается непригодной. Экспериментальные и расчетные рефракционные изображения для капли объемом $10 \mu 1$ оказались наиболее близкими при $k=4$, что соответствует представленному на рис. 3 изображению капли, которая имеет несколько „уплощенную“ верхушку, что характерно для полиномиальной аппроксимации при $k>2$.

Анализ рефракционных изображений с использованием соотношения (4) позволил установить диапазон краевых углов, наблюдаемых в эксперименте $\theta=28-42^{\circ}$ непосредственно сразу после нанесения капли на поверхность. При испарении капли краевой угол $\theta$ снижался до $7-10^{\circ}$, т.е. наблюдалось явление гистерезиса краевого угла, при этом положение линии контакта оставалось неизменным, уменьшалась только высота капли. Погрешность косвенных измерений угла $\theta$ определяется на основе соотношения (4) при известной погрешности прямых измерений геометрических параметров изображения. Размеры и положение элементов микрорельефа (рис. 3) на краях капли восстанавливались на основе изображений, полученных в широком пучке [10].

Письма в ЖТФ, 2017, том 43, вып. 13 
Предложенная методика предполагает послойное восстановление рельефа поверхности и может быть отнесена к классу лазерных рефракционных томографических методов при одноракурсном зондировании [11]. Преимущество такого подхода заключается в возможности восстановления именно рельефа поверхности капли во всех сечениях, в то время как в большинстве рассмотренных в [1-8] методах восстанавливается профиль капли при ее осесимметричной модели. Основным ограничением рассмотренной методики является предположение о прозрачности жидкости и подложки, однако принципиально возможна модификация экспериментальной установки в случае подложки из непрозрачного материала. Результаты работы могут быть использованы при решении прикладных задач биомедицины для анализа свойств жидкости, а также физики и химии поверхностей для экспериментального исследования шероховатости и гетерогенности последних, измерения краевого угла, скорости испарения и др.

Работа выполнена при финансовой поддержке Российского фонда фундаментальных исследований (проект № 14-08-00948-a).

\section{Список литературы}

[1] Емельяненко А.М., Бойнович Л.Б. // Заводская лаборатория. Диагностика материалов. 2010. Т. 76. № 9. С. 27-36.

[2] Матюхин С.И., Фроленков К.Ю. // Конденсированные среды и межфазные границы. 2013. Т. 15. № 3. С. 292-304.

[3] Del Rio O.I., Kwok D.Y., Wu R. et al. // Colloids Surf. A. 1998. V. 143. P. 197.

[4] Bateni A., Susnar S.S., Amirfazli A. et al. // Colloids Surf. A. 2003. V. 219. P. 215.

[5] Stalder A.F., Kulik G., Sage D. et al. // Colloids Surf. A. 2006. V. 286. P. 92.

[6] Канчукоев В.3. // Письма в ЖТФ. 2004. Т. 30. В. 2. С. 12-16.

[7] Зайцев Д.В., Кириченко Д.П., Кабов О.А. // Письма в ЖТФ. 2015. Т. 41. B. 11. C. $79-85$.

[8] Антонов Д.В., Волков Р.С., Пискунов М.В., Стрижак П.А. // Письма в ЖТФ. 2016. Т. 42. В. 5. С. 49-56.

[9] Pavlov I.N., Raskovskaya I.L., Rinkevichyus B.S., Tolkachev A.V. // Proc. of 10th Pacific Symposium on Flow Visualization and Image Processing. Paper ID:256.

[10] Павлов И.Н., Расковская И.Л., Ринкевичюс Б.С. // Труды 26-й Межд. конф. „Графикон 2016“. ИФТИ, ННГАСУ, 2016. С. 319-322.

[11] Расковская И.Л. // Квантовая электроника. 2013. Т. 43. № 6. С. 554-562.

Письма в ЖТФ, 2017, том 43, вып. 13 